\title{
A STUDY ON SOCIAL MEDIA OPINION ABOUT WOMEN INVESTORS
}

\author{
Nijolè MAKNICKIENĖ®1* ${ }^{*}$, Lina RAPKEVIČIŪTÉ2 \\ ${ }^{1}$ Department of Financial Engineering, Faculty of Business and Management, \\ Vilnius Gediminas Technical University, Sauletekio al. 11, LT-10223 Vilnius, Lithuania \\ ${ }^{2}$ Network Finance Decision Support, EUROC FP\&A, Western Union, \\ J. Balčikonio g. 7, LT-08247 Vilnius, Lithuania
}

Received 28 February 2021; accepted 01 April 2021

\begin{abstract}
Purpose - to investigate opinions on social networks about women's investment and its determinants. Social network sentiment research aims to find out why investing remains a very masculine area of life.

Research methodology - Twitter social network analysis tools will be used for data mining. Word clouds and sentiment index will be obtained using neural network classification algorithm based on Long Short-Term Memory (LSTM).

Findings - the paper obtained the dynamics of three-week opinions on the social network Twitter, considering the main factors that influence women's choice to invest.

Research limitations - only the main factors were investigated and only based on a survey of other authors. Data were extracted from the social network for a limited time.

Practical implications - traditionally, investing has remained an area dominated by men. However, women are becoming increasingly financially independent and increasingly involved in the investment process. Therefore, it is very important to analyze the factors that hinder the achievement of investment results.

Originality/Value - there are many scientific papers that examine the factors that determine women's investment choices. However, opinions and sentiments on social networks have not been explored.

Keywords: behavior of investor, opinion mining, sentiment analysis, text analysis, gender differences, gender finance.

JEL Classification: G4, G5.

Conference topic: Contemporary Financial Management.
\end{abstract}

\section{Introduction}

Gender equality is analysed not only in the scientific articles, but also gender equality is strategic area for European Union. European Commission has stated that diversity brings more sustainable, resilient, and profitable investment. Women invest not only to generater profit, but also to create value. Analysis shows that women invest in social areas that creatt greater value for all population. Women are force that invest more in socially responsible busines and greener busininess. But not less important is when women become more financial educated, financial intelligent, she can be social and financial independent and drive her own decision. Also, financial education and ability to invest can solve women poverty in the pension.

There were many researches performed and articles written about women and men equality. In majority areas women rights and roles are the same as men. But there is one of the last area that is left where men plays the leading role. It is investment. This area is dominate by men, almost $80 \%$ of investment is done by men and only $20 \%$ by women. Fortunately, the recent analysis shows positive signs - women start being interested in investment and find investment attractive. However, there are wide range of therories about women, who participate in the investment process, how other inverstors react to women in investment and what factors influence women investment decision. Theories tell us that woman's and men's investment behaviour is very different. For example, men are riskier than women, women invest less in riskier securities, women are more risk averse, women do not take risk, women are more emotional. There are many scientific articles that focus on general investment and do analyze, specifically

\footnotetext{
*E-mail: nijole.maknickiene@vilniustech.lt
} 
women behavior. However, there is no research completed about opinions and sentiments on social networks. The purpose of this article is to analyze opinion and sentiments on Twitter social network and factors that impact women investment choice and decision to invest.

In order to achieve this goal, the following tasks have been completed:

- Analyzed previous research completed in this area.

- Presented methodology of this paper.

- Identified keywords in investment process.

- Extracted data form Twitter separaterly for women, men, and overall investment.

- Concluded the result and presented findings.

Limitation of the study:

Data were extracted for very limited period, three weeks only. The main factors were investigated and based only on other authors. Due to limited time to analyze social networks, were chosen three factors that according to analyzed authors are the key factors that influence investment decision: risk tolerance, loss/risk aversion and education. Self-confidence was excluded from the social network analysis since based on authors opinion, it is very difficult to evaluate this factor without analyzing additional factors.

\section{Review of literature}

Investment decision is complex process that is impacted by many factors (Franka et al., 2013). Investment decision can be done based on a strategy and factors (Wu et al., 2012) or random choice that is based on emotions as it is said in the Behavioral finance theory. Women and men use different strategies in the investment process, however, different strageries do no lead to significant better or worse investment result (Powell \& Ansic, 1997). Women unsually choose to invest in the securities that she knows, rather than trying to overperformance Standard \& Poor 500 stock index (Kristof, 2016).

Behavioral finance theory tells that investment decision is not always done based on empirical analysis but rather based on emotions and leads to irrational decision (Fromlet, 2001).

Authors, who analyzed behavioral investment, were analyzing many factors that impact investment decision. Sanjeet Kumar and Prashant Kumar (2019) grouped all factors in the six categories:

- Sociocultural factors (religious reason, media, broker's recommendations for stock, family member's opinion, information obtained from internet and existing shareholders etc.).

- Personal factors (age, type of occupation, lack of awareness, increase in income level, ease of obtaining borrowed fund etc.).

- Market related factors (general business conditions, fluctuations/development in the stock market, recent price movement of a firm's stock, diversification needs etc.).

- Economic factors (dividend policy, tax benefits, regular income etc.).

- Investment specific factors (duration of investment period, terms, and conditions of investment tool, risk associated, past investment experiences etc.).

- Accounting information (return on investment, price-earnings ratio, expected earnings of company etc.).

Marwahaand and Arora (2016) analyzed 28 factors that influence investment decision such as diversification need, religious reasons, high return, liquidity, tax benefit, current economic indicator, rumors, professional management, personal financial needs of an investor. Their findings showed that the most significant factors are probable benefits factors (liquidity, convenience, capital growth, high returns, inflation resistance, flexibility).

Petric (2015) analyzed three angles of how investors make decision and build their portfolios: risk tolerance, mental accounting, and self-confidence. Mental accounting is identified as as key factor that influence individual investor (Levišauskaite \& Kartašova, 2011). There are more authors who identify that risk tolerance is one of the most important factor for decision making (Gibson et al., 2013). Risk tolerance as an investment factor can impact investor positively, negatively or neutrally (Zandri \& Sune, 2019; Mittal \& Vyas, 2011). Most commonly bad decision that led to lose money, impacts investor negatively, because decision that was made will associate with negative experience when investor lost his investment (Zhou \& Buongiono, 2019). Men and women react to prior losses differently: men are willing to continue invest, but majority of women tend to discontinue investing or expect losses in the future (Hibbert et al., 2018), because prior losses or gains impact future decision making (Thaler \& Johnson, 1990). Additionally, bad investment decision associates with stress (Steve, 2020) and mood (Gul \& Khan, 2019). Moreover, sometimes investor makes non-rational decision willing to reduce the risk but at the same time reduce investment profit too (Zhou \& Buongiono, 2019). Every investor has different tolerance level, but sometimes risk tolerance level can be affected by mood (Gul \& Khan, 2019). Also, risk tolerance level can be grouped. One of grouping measurement is age (Jaggia \& Thosar, 2000). Also, majority of the studies showed that women tolerate lower risk level compare to men (Zandri \& Sune, 2019; Skonieczna \& Castellano, 2020) and women are risk averse (Kashyap et al., 2019; Seddik Meziani \& Noma, 2018). On the other hand, there are studies that identify that women and men tolerate the same risk level (Nelson, 2016). 
According to Petric (2015), risk tolerance and education has direct relationship: risk aversion decreases with the level of education and women are more likely to averse risk than men. Risk aversion is not always only the source of financial loss, but behind the main reason can be hidden others, such as loss of community, reputation, or the perception of others (Steve, 2020).

If risk averse factor impacts investment decision it can lead to bad investment result or no decision and stress (Steve, 2020). Also, risk averse does not allow to optimize investment (Yuji, 2020).

Another important factor that impacts investment choice and decision is education (Petric, 2015; Liivamägi et al., 2019). Education has significant impact on investment decision and correlates positively (Guiso \& Jappelli, 2005), better educated investors more actively participate in investment process and are more willing to invest (Liivamägi et al., 2019; Yang, 2013). Educated investor diversifies his portfolio and decrease investment risk (Goetzmann \& Kumar, 2008). Diversification is one of the key factors that influence investment decision (Nagy \& Obenberger, 1994). However, men who have high status invest more than women who have high status (Markovits et al., 2017).

Analysis showed that investor can be impacted by many different factors: social, personal, economic, market and investment specific. Many different factors create very complex investment decision process. Factors that drive investment decision are different in context of gender. Women has lower risk tolerance and are more risk averse compare to men: men mostly invest to gain profit, women - are more socially responsible and invest in sustainable areas. Another important factor, that can make investment more accessible to women is education, which correlates positively with investment, the higher education investor has, the more invest. Also, according to analyzed authors, there is significant difference between women and men investment decision and how curtain factors influens their behavior. All these findings about the factors that influence investment decision and investment choice will be analysed further on social network Twitter.

\section{Metodology of opinion extraction and valuation}

Social networks have become a place of huge, often contradictory flows of information in the modern world. Assessing and analyzing those flows can uncover societal problems and inspire solutions to those problems. Classifying records by keywords allows us to get to know the chosen area more deeply. Assessing the positivity and negativity of a record set al.ows us to get an estimate of the balance of opposite information flows called sentiment score. The ratio of positive and negative entries describes the balance of the participants in the discussion according to their opinions, allows to assess which group of people in the discussion is larger and how much.

Community opinion influences people's choices, as evolution has shaped the need for human to feel comfortable in society and try not to confront. This work aims to explore differences in opinions on social networks about men's investment, women's investment, and simply investment. First, the authors created a set of keywords that describe the investment process. Keywords are used to extract data from twitter posts using the data visualization tool (Tweet, n.d.). All data are attributed to women, men or simply investment. Sentiment analysis is then performed using the matlab algorithm (MathWorks, n.d.). The sentiment classifier is using steb by step:

- Loading a prepared textul data attributed to women, men and simply investment separately. The amount of data on each keyword can reveal the importance of the phenomenon under study in the community.

- Loading an opinion lexicon listing positive and negative words. Dictionaries will be used to assess the positivity and negativity of the words and sentences in twitter posts.

- Training a sentiment classifier using the word vectors of the positive and negative words. The result of this step is confusion matrix, which value the accurasy of classification (Figure 1).

- Sentiment analysis. Kode visualize the prepared data in word clouds and gives the sentiment scores to each twit. The mean sentiment scores are calculating fore each textual data set.

The comparison of sentiment scores according to keywords can explain prevailing opinions in social network and reveal which aspects of public opinion are the most obstacles to achieving a gender balance in the investment process.

\section{Investigation of social media opinions about women and men investment differneces}

Data mining. Data was collected throughout the month from the Twiter social network using a special tool (Tweet, n.d.). Keywords are chosen to reflect different aspects of investing:

- Invest. This keyword is chosen to understand general

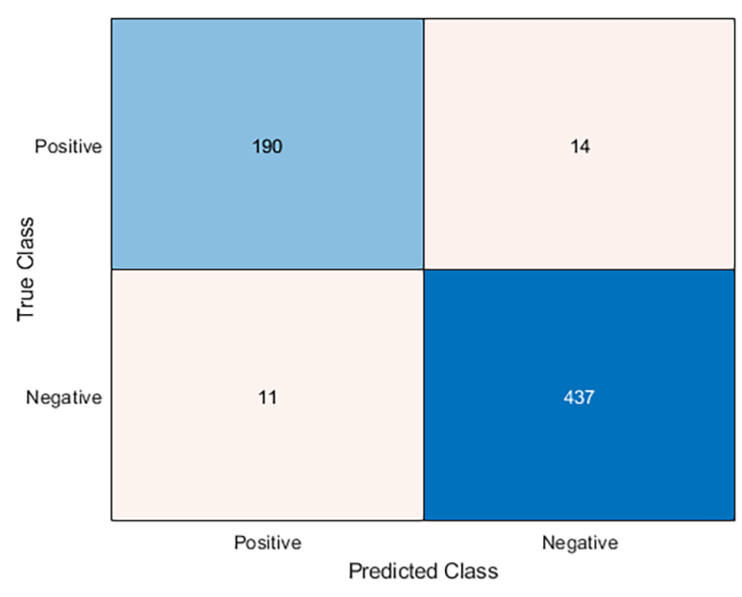

Figure 1. Confusion matrix of classification (source: created by the authors) 
opinion about investment on the social network and motive of the investment. Also, understand with what opinion social network users associate investment process: positiveness, negativiness or neutrality.

- Men/male invest and women/female invest. This keyword is chosen to understand opinion about men and women participation in the investment process and sentiments it creates. To the general keyword "invest", was added additional word "female/women and male/men". In addition, "Women/female invest" keyword is chosen to understand women position in the investment process, to confirm or reject that investment is men area and majority of the investor are men.

- Invest choice. This keyword is chosen to identify the reasons which impact investment decision. Analysing collected data based on this keyword, key investment indicator can be revealed. Adding gender "men/male or women/female" reveals difference between men and women investment choice. Also, shows factors that have impact on women and men investment choice separaterly and how significant factors are by gender.

- Invest education. This keyword is chosen to analyse what impact, of education level, is to investment choice and whether is diferenciation between men and women investors. After literature analysis, is decided separaterly analyse education factor on investment choice since majority of the analyzed authors determined education as key factor that has significant impact on investment choice. Education level reveals risk tolerance level investor is willing to take: the deeper knowledge investors have on investment process, the riskier investment decision investors are willing to make.

- Risk tolerances invest. This keyword is chosen to analyse what impact of risk tolerance level has on expected return. Also, to identify if risk tolerance level exists and if it exists how risk tolerance level diferenciates between gender. Furthermore, risk tolerance level reveals purpose of the investment. If purpose of the investment is to keep money save or reduce inflation impact on savings, then usually investors keep their money in the back deposit, government bonds etc. and tolerate very low risk. Investors with higher tolerance level, unsually invest in ETFs, mutual funds, and stocks. Their purpose of investment is high return, the higher required return implies that investor should accept higher risk.

- Loss averse. This keyword is chosen to understand investor expectation of the investment: whether negative or positive past investment choice has any impact on the future investment choice. Usually, if investor averse loss, it shows that in the past investor made wrong investment decision and past investment associates with bad investment that makes impact on the future investment decision. Women investors are more loss averse than men. This assumption is also examined.

- Invest decision. This keyword is chosen to identify investor types that domintes on the social network, focusing on two types of investors First, who have clear strategy and make investment decision on clearly identified rules. Second, investors who have no clear rules and guidliness, but rather make their decision based on feeling.

All the above-described keywords are analysed from the three perspective: general, not taking into consideration gender, men and women. Separaterly analyzed each factor can show differences between men and women, but do not show true cause of investment choice. Investment choice is usually impacted by several factors. Assumptions that are only made based on separate factors may led to incorrect conclusions. For example, if investor has low risk tolerance level, the following assumptions might be applicable:

- Investor made bad investment decision in the past that resulted in negative profit and investor tries to reduce loss possibility for the future investment.

- Investor has lower education level and his knowledge about investment is limited.

- Investor is female.

- Investor has passive investment strategy.

These example shows that conclusion about investment choice should be made based on the complete and full investor profile. The accumulated data set was later used in sentiment analysis. The amount of data, their distribution by selected keywords reflects the popularity of the topic in the Twitter community. The data show that posts on Twitter are generally not disaggregated by gender. In the study of the investment process (Figure 2a), records attributed to men or women account for only 18-20\%. When looking at the individual sub-themes related to investment (Figure $2 \mathrm{~b}$ ), the ratio is veri small $(1-4 \%)$, this means that the social networking community does not link these aspects to gender, or the community takes for granted what the gender of the investor is. The exception is "risk tolerance": $29 \%$ of risk tolerance records are associated with male investment and $41 \%$ with female investment.

The number of Twitter posts related to investor gender and individual subtopics was examined separately (Figure 2c), and it can be observed that investment education and risk tolerance have more reports related to women than to men, while in other subtopics the opposite is true. By examining the distribution of the data, it is possible to examine the content of the data.

Word clouds. Word cloud is a visualization tool that provides word statistics in a dataset. Word clouds do not answer a specific question as a survey but reflect a field of topic descriptions used in the community. During the research, we obtained and analyzed word clouds for all aspects of investment in general and in relation to the gender of the investor. The overall word cloud for the investment process is shown in Figure 3 and related to men's investment and women's investment in Figure 4. 
a)

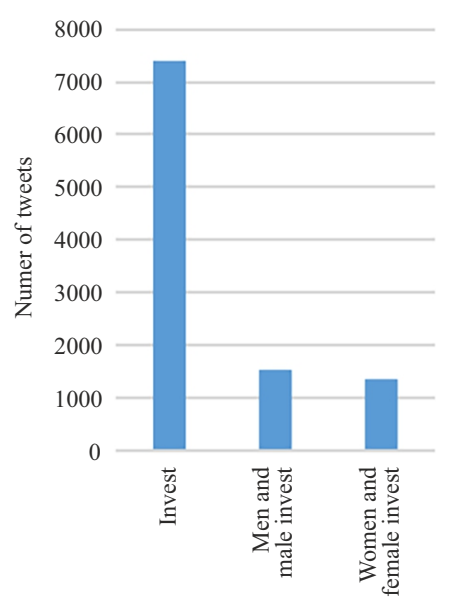

b)

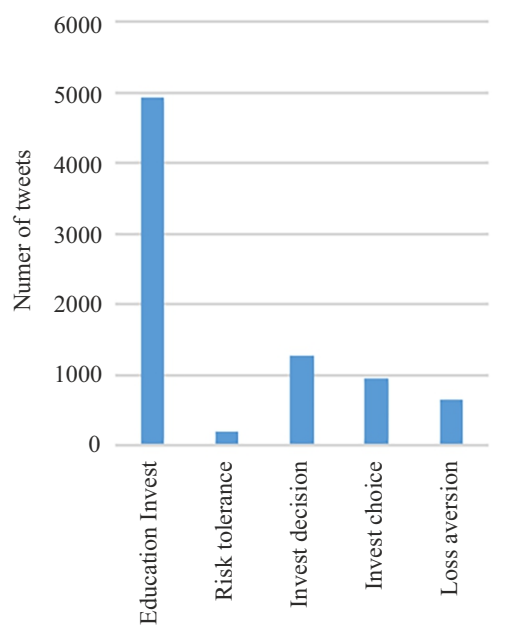

c)

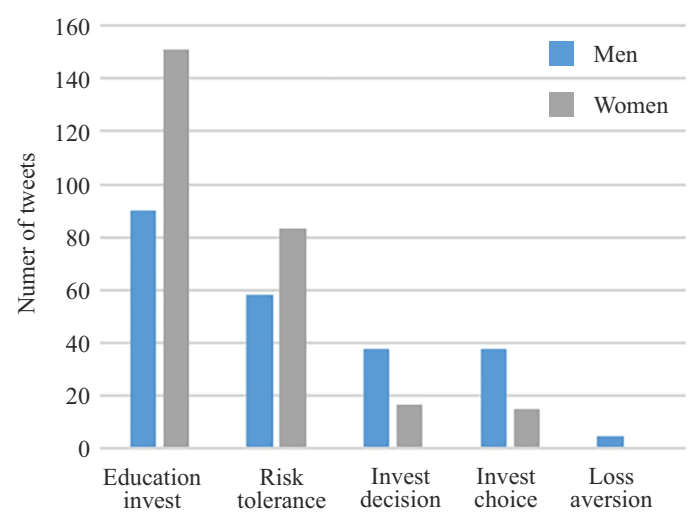

Figure 2. Distribution of data accordin keywords: a) investing in general and by gender; b) the general popularity of investment topics; c) investment themes by gender (source: created by the authors)

Predicted Positive Sentiment

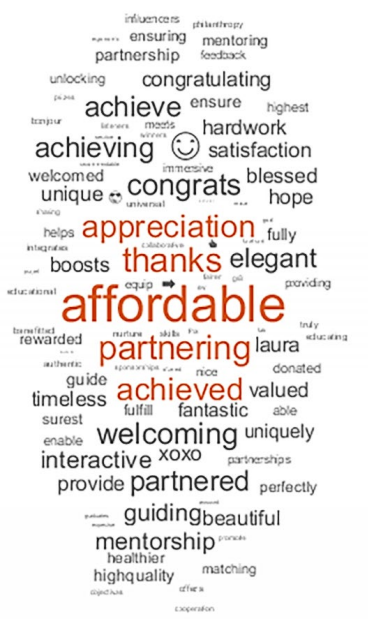

$$
\begin{aligned}
& \text { acing compounding } \\
& \text { penalized unbalanced } \\
& \text { outdated fishy } \\
& \text { shut blaming forced } \\
& \text { evict cooket soos sissy } \\
& \text { abrupt evicted naira } \\
& \text { snitches crOakerconspiracy } \\
& \text { shutdowns decaying } \\
& \text { disrupted bro brunt worry telltale } \\
& \text { warned fearing shuts } \\
& \text { overvalued illiquid collapse } \\
& \text { choking trampled piling } \\
& \text { deforestation } \\
& \text { factional lashing } \\
& \text { unpreparedness }
\end{aligned}
$$

Figure 3. Word clauds for keyword "invest" (source: created by the authors)

a)

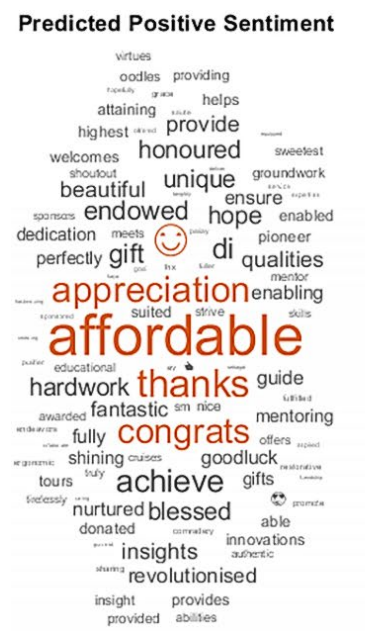

b)

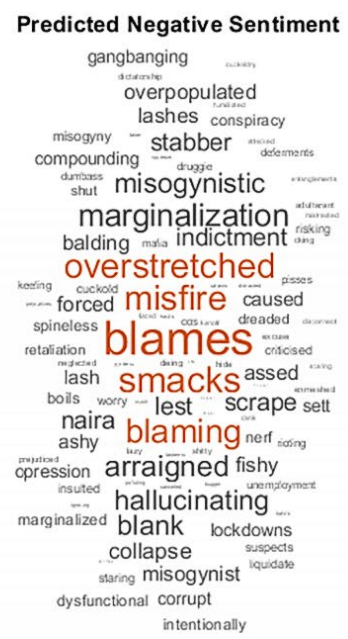

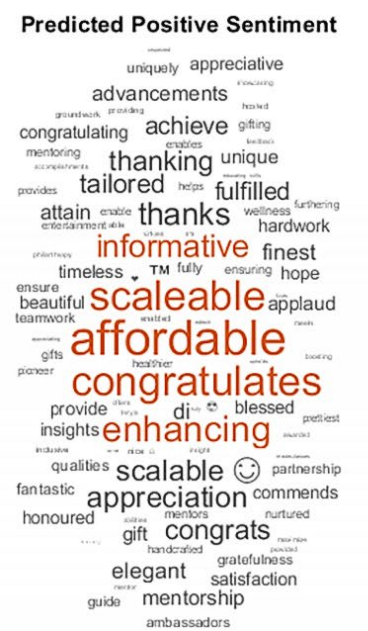

Predicted Negative Sentiment

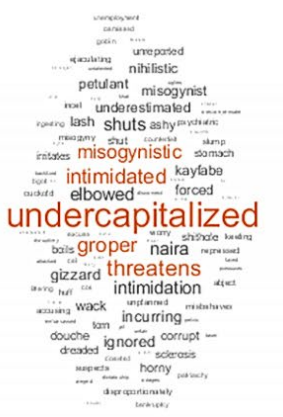

Figure 4. Word clauds for keyword "invest": a) men and male; b) women and female (source: created by the authors) 
Examining positive sentiments in the presented word clouds, it can be seen that emotions are expressed in the same words: affordable, thanks, appreciation, congrats. There are a lot of overlaps in the cloud of positive words about investing and investing tied to male investors. However, women's investment is associated with other words that express positive emotions: enhuncing, scalable, informative.

Examining the cloud of negative words, we see that the most commonly used words are not repeated in all three word clouds. All the negative words in the clouds of words are associated with fear, failure, blaming. A cloud of words associated with women investing is still associated with intimidation and threats.

This method of research is quick and inclusive because it reveals positive and negative emotions, although it often raises more questions than answers, which leads to more detailed research.

Sentiment scores. We selected two indicators for the evaluation of sentiments:

- Sentiment score, which evaluates the average of all record words positivity or negativity. A certain amount of textual data will be considered positive with a positive number and a negative text will be scored with a negative number.

- Part of positive tweets value the share of positive posts on the social network in the set of all posts. It assesses which part of the social networking community has positive emotions according to selected keyword. The rest part of tweets is negative.

Sentiment data is presented in Table 1. Examining the different aspects of investing in a gender-disaggregated way, we can see that all investment aspects received a positive assessment. The most positive sentiment score was obtained by assessing investment education (0.76), the least - risk tolerance, but here too the assessment is positive (0.35). Investment education in word clouds is usually described by the following positive words: affordable, worldclass, achieved, thanks and thanking. And negative emotions are expressed in the most common words: mismanaging, bluming, unnecessary, absenteeism. The following positive words are assigned to risk tolerance: personable, thanks, tailored, unique. Negatives: stomach, boils, shut, risking, worry.

The evaluation of men's and women's investment aspects in the social network is usually expressed by a positive sentiment scores. The highest sentiment score rated women's investment decision (0.79), and the lowest positive men's investment decision (0.29). In all categories, the investment aspects of women were assessed with a higher positive sentiment score than men. However, risk tolerance has negative sentiment scores: male scored by -0.01 , female - by -0.22 . Examining the word cloud, it was found that the most negative negative risk tolerance of men is described by the words: orrupt, stomach, bankruptcy, shut, shorted. And women's risk tolerance is described by the following negative words: orced, disrupts, shut, microaggressions, mutilated.

The proportion of positive entries in all categories of investment aspects with and without gender is between 54\% and $91 \%$, with the exception for the risk tolerance aspect. Here we have the majority in the negative. The study revealed that risk tolerance is an especially important aspect in assessing the gender balance in the investment process.

Extracting community opinion from the social network twitter using big data analytics tools does not solve society and even more so economic problems, but can show where the root of the problem is. Knowing the investment aspects that are most closely linked to gender imbalances can lead to the search for the right solutions.

Table 1. Sentiments according to different keywords in social media (source: created by the authors)

\begin{tabular}{|l|c|c|}
\hline \multicolumn{1}{|c|}{ Keywords } & Sentiment scores & Part of positive tweets \\
\hline Invest & 0.4621 & 0.77 \\
Men and male invest & 0.2138 & 0.54 \\
Women and female invest & 0.3960 & 0.68 \\
\hline Invest education & 0.7564 & 0.91 \\
Invest education men and male & 0.4818 & 0.87 \\
Invest education women and female & 0.5904 & 0.88 \\
\hline Risk tolerance invest & 0.3530 & 0.78 \\
Men and male risk tolerance & -0.0107 & 0.48 \\
Women and female risk tolerance & -0.2145 & 0.23 \\
\hline Invest decision, objective & 0.4169 & 0.84 \\
Men and male invest decision & 0.2934 & 0.71 \\
Women and female invest decision & 0.7935 & 0.88 \\
\hline Invest choice & 0.4966 & 0.83 \\
Men and male invest choice & 0.2812 & 0.74 \\
Woman and female invest choice & 0.3109 & 0.67 \\
\hline
\end{tabular}




\section{Conclusions}

Extracting data from social networks is radically different from a survey. Twitter data is not considered a post. These are depersonalized data, the content of which is analyzed by the methods of big data analysis. Texts obtained from the social network reflect the prevailing opinions in the community. Keyword selection is an important part of data mining. The keywords chosen for the study allow to compare separate aspects of investing with each other, separate aspects of investing for men and women, and to distinguish where gendering problems occur and where not.

Data extraction from the social network Twitter using keywords revealed that the investment process itself is related to gender in only $18-20 \%$ of all records. Most aspects of investing are usually unrelated to gender. In terms of gender, investment education, investment decisions, investment choices and loss aversion account for only $1-4 \%$ of the total number of records. Examining separate aspects of investment, it was found that investment education and risk tolerance are more related to women than to men. When in the meantime other aspects of investing are the opposite.

Visualizing data using a word cloud reveals a field of interest for social network participants. The clouds of words associated with investing, investing men and women separately, reveal that positive emotions are all expressed in the same words. However, negative emotions are expressed in different words in each case studied.

Data mining and sentiment research revealed that gendering problems may be associated with investment education and risk tolerance. Risk tolerance is the only aspect of investment that received a negative sentiment score and garnered the least positive records. Comparing the assessment of risk tolerance between men and women, we get a huge difference $(-0.21$ for women and -0.01 for men) of sentiment scores. There are more positive posts on Twitter during the study period than there are more than negative ones on all topics except risk tolerance by gender. Here, a particularly small proportion of social network participants are positive about women's risk tolerance - only $23 \%$, while men $-48 \%$. The causes of gender imbalances in investment can be sought in the area of risk tolerance and opportunities can be sought to address this problem, such as hedging strategies, investment insurance, and so on.

\section{References}

Franka, S. G., Souza de Souzab, D. V., Duarte Ribeiroa, J. L., \& Echeveste, M. E. (2013). A framework for decision-making in investment alternatives selection. International Journal of Production Research, 51, 5866-5883. https://doi.org/10.1080/00207543.2013.802393

Fromlet, H. (2001). Behavioral finance theory: systematic analysis of departures from the homo economicus paradigm are essential for realistic financial research and analysis. Business Economics, 36, 63-70. https://doi.org/10.15611/pn.2015.401.19

Gibson, R., Michayluk, D., \& Van de Venter, G. (2013). Financial risk tolerance: An analysis of unexplored factors. Financial Services Review, 22, 23-50.

Goetzmann, W. N., \& Kumar, A. (2008). Equity portfolio diversification. Review of Finance, 12(3), 433-463. https://doi.org/10.1093/rof/rfn005

Guiso, L., \& Jappelli, T. (2005). Awareness and stock market participation. Review of Finance, 9, 537-567. https://doi.org/10.1007/s10679-005-5000-8

Gul, F., \& Khan, K. (2019). An empirical study of investor attitudinal factors influencing herd behavior: evidence from Pakistan stock exchange. Abasyn University Journal of Social Sciences, 12(1), 1-11. https://doi.org/10.34091/AJSS.12.1.01

Hibbert, A. M., Lawrence, E., \& Prakash, A. J. (2018). The effect of prior investment outcomes on future investment decisions: Is there a gender difference? Review of Finance, 22, 1195-1212. https://doi.org/10.1093/rof/rfw060

Yang, A. S. (2013). Decision making for individual investors: a measurement of latent difficulties. Journal of Financial Services Research, 44, 303-329. https://doi.org/10.1007/s10693-012-0144-0

Yuji, Y. (2020). Portfolio optimization in fuzzy asset management with coherent risk measures derived from risk averse utility. Neural Computing \& Applications, 32, 10847-10857. https://doi.org/10.1007/s00521-018-3683-y

Jaggia, S., \& Thosar, S. (2000). Risk aversion and the investment horizon: a new perspective on the time diversification debate. The Journal of Psychology and Financial Markets, 1, 211-215. https://doi.org/10.1207/S15327760JPFM0134_6

Kashyap, N., Bansal, A., Mehta, P., \& Kumar, R. K. (2019). Gender differences in selection of investment avenues in Solan town of Himachal Pradesh. International Journal of Bioresource and Stress Management, 10, 9-18. https://doi.org/10.23910/IJBSM/2019.10.1.1931

Kristof, K. (2016). The secrects of women investors. Kiplinger's Personal Finance, 70, 4-50.

Kumar, S., \& Kumar, P. (2019). Factors influencing the investment behavior of women investors: an empirical investigation. Journal of Financial Risk Management, 16, 30-51.

Levišauskaitė, K., \& Kartašova, J. (2011). Evaluation of irrational individual investors' behavior driving factors in Lithuania. Applied Economics: Systematic Research, 5, 119-130.

Liivamägi, K., Tarvo, V., \& Tõnn, T. (2019). Investor education and IPO participation. Emerging Markets Finance \& Trade, 55, 545-561. https://doi.org/10.1080/1540496X.2018.1443806

Markovits, H., Gauthier, E., Gagnon-St-Pierre, E., \& Benenson, J. F. (2017). High status males invest more than high status females in lower status same-sex collaborators. PLoS ONE, 12, 1-13. https://doi.org/10.1371/journal.pone.0185408

Marwahaand, K., \& Arora, S. (2016). A factors influencing investors towards investing in FD's. Vishwakarma Business Review, $6,71-81$. 
MathWorks. (n.d.). Train a sentiment classifier - MATLAB \& Simulink. Retrieved January 14, 2021, from https://se.mathworks. com/help/textanalytics/ug/train-asentiment-classifier.html

Mittal, M., \& Vyas, R. K. (2011). A study of psychological reasons for gender differences in preferences for risk and investment decision making. IUP Journal of Behavioral Finance, 8, 45-60.

Nagy, R. A., \& Obenberger, R. W. (1994). Factors influencing individual investor behavior. Financial Analysts Journal, 50, 63-68. https://doi.org/10.2469/faj.v50.n4.63

Nelson, J. A. (2016). Not so strong evidence for gender difference in risk taking. Feminist Economics, 22, $114-142$. https://doi.org/10.1080/13545701.2015.1057609

Petric, I. A. (2015). Psychological factors influencing market investment in Romania. Review of Management \& Economic Engineering, 14, 331-343.

Powell, M., \& Ansic, D. (1997). Gender differences in risk behaviour in financial decision-making: an experimental analysis. Journal of Economic Psychology, 18, 605-628. https://doi.org/10.1016/S0167-4870(97)00026-3

Seddik Meziani, A., \& Noma, E. (2018). A new method of measuring financial risk aversion using hypothetical investment preferences: what does it say in the case of gender differences? Journal of Behavioral Finance, 19(4), 450-461. https://doi.org/10.1080/15427560.2018.1431888

Skonieczna, A., \& Castellano, L. (2020). Gender smart financing investing. In and with women: opportunities for Europe (Discussion Paper No. 129). Publications Office of the European Union.

Steve, P. (2020). The risk of being risk averse and what to do about it. Journal of Financial Service Professionals, 74, 31-35.

Thaler, R. H., \& Johnson, E. J. (1990). Gambling with the house money and trying to break even: the effects of prior outcomes on risky choice. Management Science, 36, 643-660. https://doi.org/10.1287/mnsc.36.6.643

Tweet. (n.d.). Tweet sentiment visualisation App. Retrieved January 14, 2021, from https://www.csc2.ncsu.edu/faculty/healey/ tweet_viz/tweet_app/

Wu, W., Kou, G., Peng, Y., \& Ergu, D. (2012). Improved AHP-group decision making for investment strategy selection. Technology and Economic Development of Economy, 18, 299-316. https://doi.org/10.3846/20294913.2012.680520

Zandri, D., \& Sune, F. (2019). Risk tolerance of South African investors: marital status and gender. Gender \& Behaviour, 17, 12999-13006.

Zhou, M., \& Buongiono, J. (2019). Optimal forest management under financial risk aversion with discounted Markov decision process models. Canadian Journal of Forest Research, 49, 802-809. https://doi.org/10.1139/cjfr-2018-0532 